\title{
Macroanatomical and histological study of the structure of intercornual gland in Abaza (Capra Aegagrus) and Gurcu (Capra Falconeri) goats breeds
}

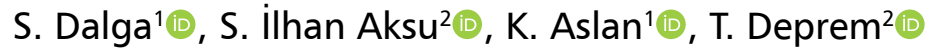 \\ ${ }^{1}$ Department of Anatomy, Faculty of Veterinary Medicine, Kafkas University, Kars, Turkey \\ 2Department of Histology and Embriology, Faculty of Veterinary Medicine, Kafkas University, Kars, Turkey
}

[Received: 10 January 2020; Accepted: 18 February 2020]

Background: The anatomical localisation of the odour glands, which increase activity during the reproduction period and help goat species to find each other, varies. Materials and methods: In our study, the anatomical and histological structures of the glands around the horn were examined in the Gurcu and Abaza goats, which are native breeds. In this study a total of 12 Abaza and Gurcu goat heads were used.

Results: The area between the two horns and area at the back of the horns were shaved to remove all hair. The distance between the horns of both goat breeds was measured using an electronic calliper. The mean distance between the horns of the Abaza goats was determined as $36.80 \pm 8.62 \mathrm{~mm}$ while this distance was $39.63 \pm 4.10 \mathrm{~mm}$ for the Gurcu goats. Gland tissue that could not be seen anatomically under the skin was examined histologically. For the histological examination, skin samples were taken from the anterior, middle, right posterior and left posterior of the area between the two horns of both breeds. Crossman triple staining and haematoxylin and eosin staining were applied to the samples. Conclusions: Glandula intercornualis was found to be slightly caudal between the horns in both breeds and normal sebaceous glands were almost absent in the areas where these glands were found. Lobes and branched alveolar glands were located around the hair follicles. (Folia Morphol 2021; 80, 1: 204-209)

Key words: horn gland, Abaza goat, Gurcu goat

\section{INTRODUCTION}

Abaza goats are farmed in the province of Artvin in Turkey and are generally bronze, white, black or brown [1]. Their mouths, horns, legs and the area around their eyes are generally black. They have a thin body structure and therefore likened to gazelles. The bucks have sword-like flat broad horns, while the females may or may not have horns. It is also known that Abaza goats are of Capra aegagrus origin [3].
Gurcu goats, also known as Tbilisi goats or Caucasian goats, are originally from the Caucasus and are bred in the North-Eastern region of Turkey, especially in the province of Kars and Ardahan. Gurcu goats, which are mostly black, grey or white, originate from the auger horned goat Capra falconeri, and are particularly similar to Abaza goats reared in Şavşat or Borçka $[3,14]$. Gurcu goats have long and straight horns that meet at the end which distinguishes

Address for correspondence: Dr. S. Dalga, Department of Anatomy, Faculty of Veterinary Medicine, Kafkas University, Kars, Turkey, 36100 , tel +905415820218, e-mail: sdalga91@gmail.com 
them from hair goats. Gurcu goats can also be hornless $[3,16]$.

The horn glands in the horn roots of goats are sebaceous glands and the goats emit an odour through these glands to find their mates during breeding periods [8]. The secretion of the modified sebaceous glands was also believed to be involved in the production of this fragrance $[2,4,10,13]$. French [9] stated that the presence of horns in male goats was a characteristic of Italian goats. Sar and Calhoun [13] reported large, branched, alveolar and sebaceous glands at the base of the horns and ears of American goats. Jenkinson et al. [10] reported that the odour of British Saanen goats mainly comes from enlarged sebaceous glands located in the head and neck. Bal and Ghoshal [2] reported that the cross-section diameters of female and castrated male fat cells are larger than male fat cells American goats, and the glands are more active during breeding season. Sar and Calhoun [13] and Bal and Ghoshal [2] described the sebaceous glands between the horn glands as being simple, branched or alveolar. According to Bal and Ghoshal [2], although females had sebaceous glands, they had no characteristic odour. In other studies in the literature, it has been reported that testosterone increases the size and activity of the sebaceous glands $[7,15]$.

Various anatomical and histological studies have been conducted on the horn glands and sebaceous glands of goats found in different parts of their bodies $[5,12]$.

Various studies have been conducted on goat breeds native to Turkey $[6,11]$. However, no anatomical and histological studies have been conducted on Abaza and Gurcu goats. Thus, in the present study, the glandula intercornualis, special skin glands located between the two horns of Abaza and Gurcu goats, was studied.

\section{MATERIALS AND METHODS}

This study was approved by the local Ethics Commission of Experimental Animals of Kafkas University. A total of 12 Abaza and Gurcu goat heads were used in the present study (regardless of gender). The materials were supplied during the sale of the Abaza and Gurcu goat herd sacrificial and forbearance from Kafkas University Education, Research and Application Farm. The head samples were obtained between June and December. Firstly, the anterior and posterior of the heads and the area between the two horns were shaved to remove all hair. The distance between the two horns of both goat breeds was then measured using an electronic calliper. The left and right horn lengths and the transverse surface of the horns of both goat breeds were measured using a tape measure. Subsequently, for the histological examination, skin samples of approximately $1 \times 1$ size were taken from the anterior, middle, right posterior and left posterior of the area between the two horns of both breeds. The skin samples were kept in $10 \%$ formaldehyde for 24 hours and then underwent routine histological follow-up (alcohol-xylol) series and paraffin-blocked. Crossman triple staining and haematoxylin and eosin staining were applied to the samples by taking $5-6$ sections with microtome from these blocks. After the staining, the samples were examined under a light microscope (Olympus $B \times 51$, Japan). The locations of the horn glands detected in both goat breeds were photographed.

\section{RESULTS}

\section{Macroanatomic findings}

The distance between the horns of the Abaza and Gurcu goat was measured using an electronic calliper. The mean distance between the horns of the Abaza goats was $36.80 \pm 8.62 \mathrm{~mm}$ while this distance was $39.63 \pm 4.10 \mathrm{~mm}$ for the Gurcu goats. The mean horn lengths for the Abaza and Gurcu goats were $276.66 \mathrm{~mm}$ and $288.66 \mathrm{~mm}$, and the transverse surface lengths of the horns were $193.33 \mathrm{~mm}$ and $218.33 \mathrm{~mm}$, respectively. Similarly, the mean horn lengths of the right and left horns of the Gurcu goats were $382.5 \mathrm{~mm}$ and $395 \mathrm{~mm}$ and their transverse surface lengths were $170 \mathrm{~mm}$ and $175 \mathrm{~mm}$, respectively. As a result of the macro-anatomical analyses performed, the presence of glandula intercornualis, which can be seen in various goat breeds macroscopically, was not found in the samples used in this study (Figs. 1, 2).

\section{Histological findings}

As a result of the light microscopic examinations conducted on the skin samples, it was observed that both goat breeds contained layers of epidermis, dermis and muscle (Fig. 3). The epidermis layer was found to be multi-layered and have a flat epithelium and microscopic papillae. Under the epidermis, there were the stratum papillare (str. superficiale) and stratum reticular (str. profundum) substrates of the dermis, as well as the connective tissue of the dermis, vessels, veins, hair roots and hair muscles (Figs. 4, 5). It was 


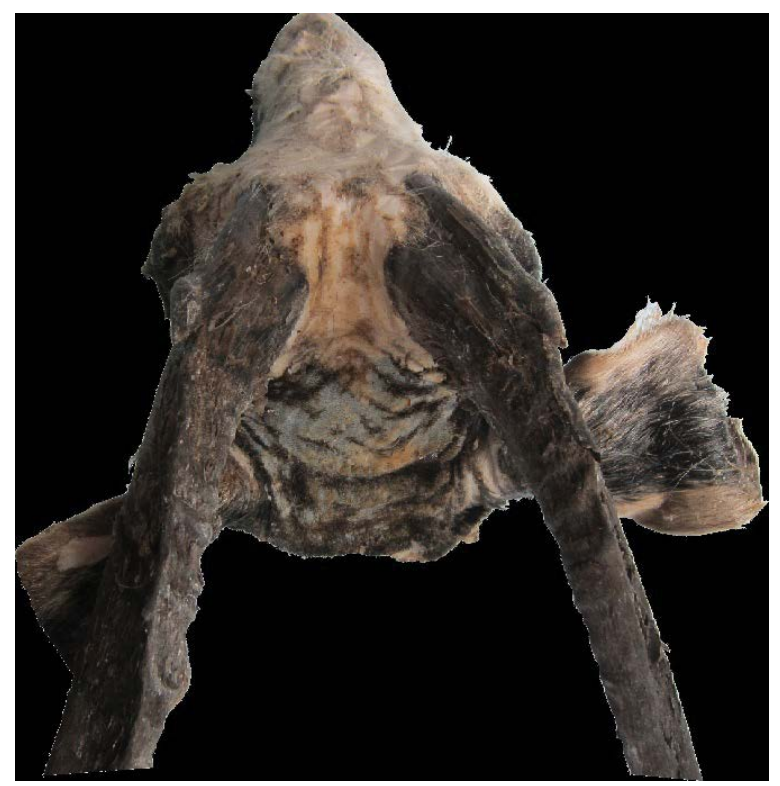

Figure 1. The horns of an Abaza goat.

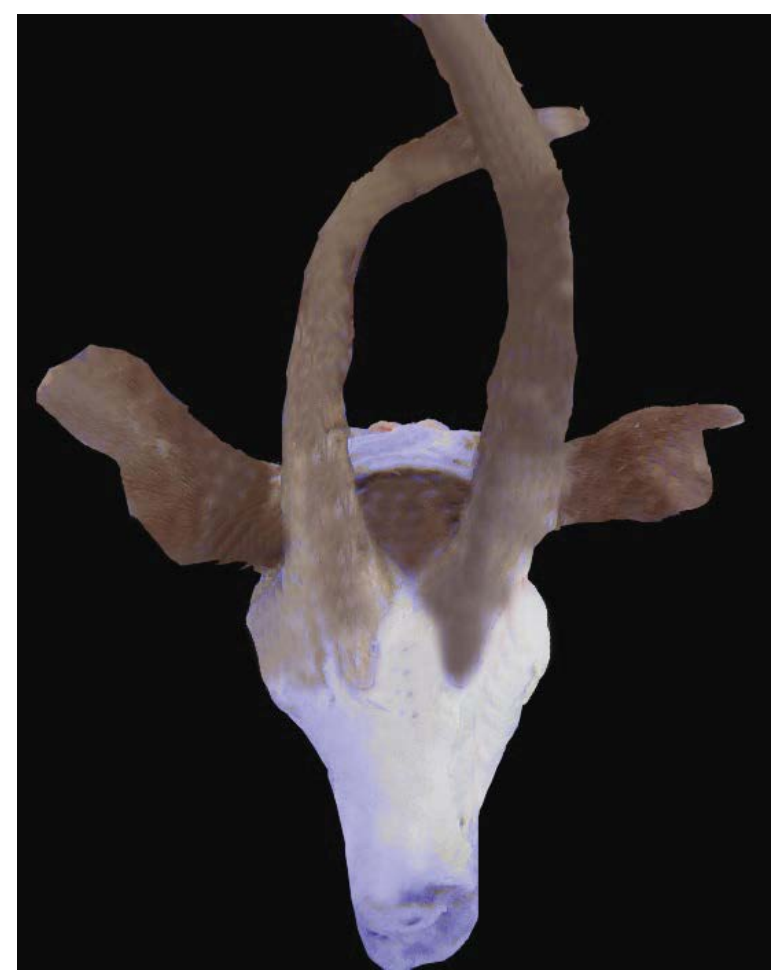

Figure 2. The horns of a Gurcu goat.

seen that the sebaceous glands that have a plurivacuolar structure and contain oil droplets were open at the hair roots (Fig. 6). In addition, the presence of sweat gland drainage duct structure was determined in both goat breeds (Fig. 5).

After the gland structures of the two goat breeds were determined, normal sebaceous gland structure

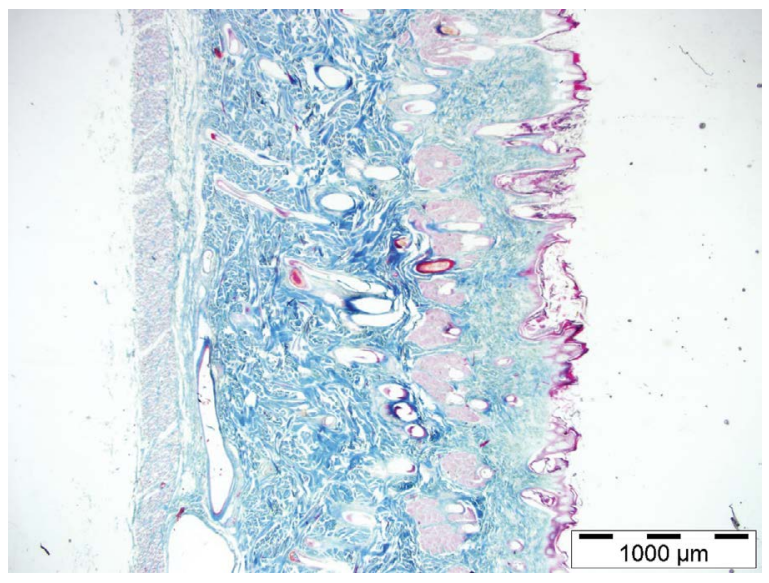

Figure 3. Microscopic view of the skin of goats; triple $\times 2$.

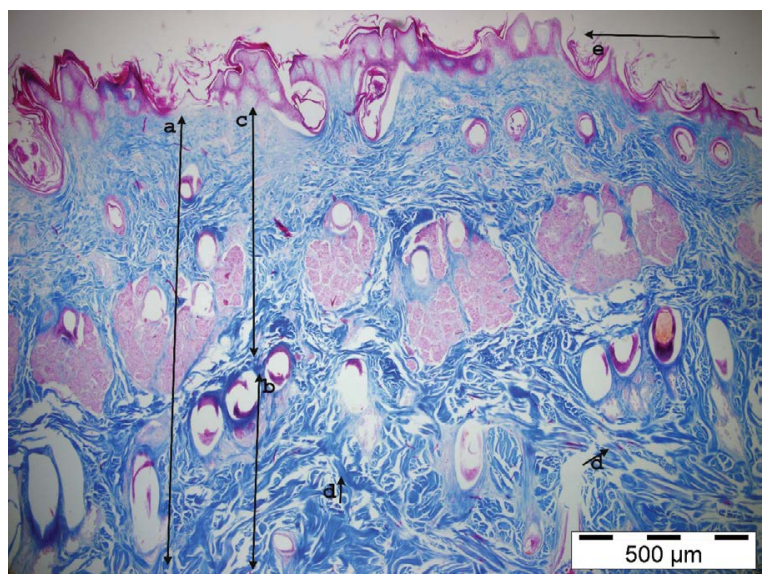

Figure 4. Dermis layers of in the goats; $a-$ dermis; $b-$ stratum polymorphic; $c$ - stratum superficial; $d$ - collagen yarns; $\mathrm{e}$ - epidermis.

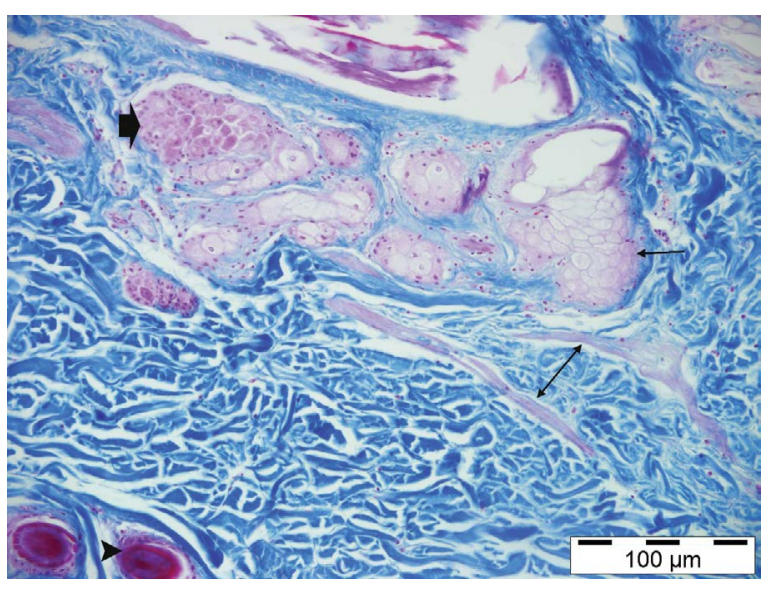

Figure 5. Dermis structures of the goats. Arrowhead: hair root; thin arrow: sebaceous glands; thick arrow: sebaceous gland-like structures; double headed arrow: muscle erector battery; triple $\times 20$.

(Fig. 7) was observed to be intense behind the horn and less localised in the anterior parts. In the present 


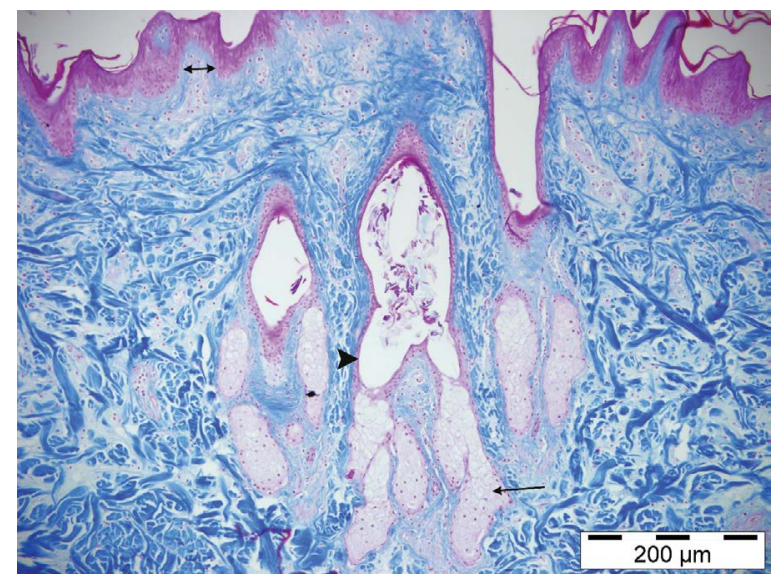

Figure 6. The opening of the sebaceous glands to the hair root in the dermis. Thin arrow: sebaceous glands, arrowhead: hair root, double-headed arrow: multi-layer epithelial structure.

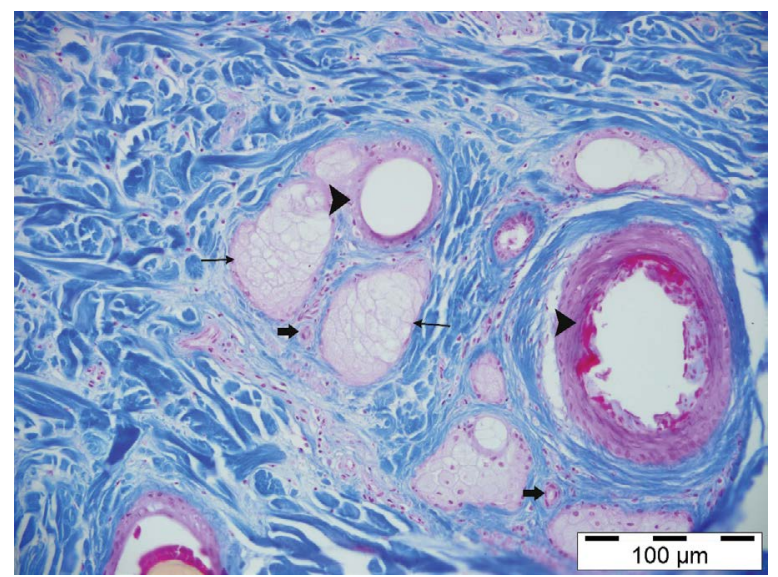

Figure 7. Microscopic view of a hair follicle, sebaceous gland and sweat gland drainage duct. Arrowhead: hair root, thin arrow: oil glands, thick arrow: sweat gland duct.

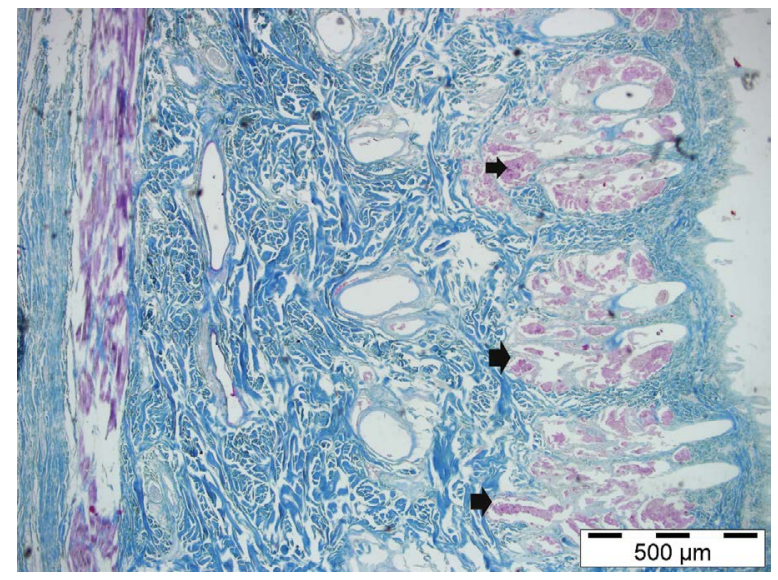

Figure 8. Localisation of the glands in stratum superficiale of the Gurcu goats. Thick arrow: triple $\times 4$, similar to the sebaceous gland structures.

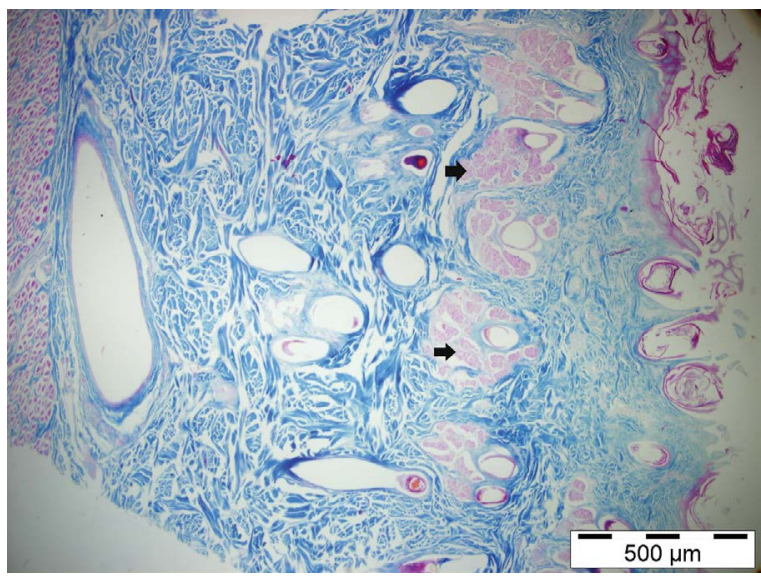

Figure 9. Localisation of the glands in the stratum superficiale of the Abaza goats. Thick arrow: triple $\times 4$, similar to the sebaceous gland structures.

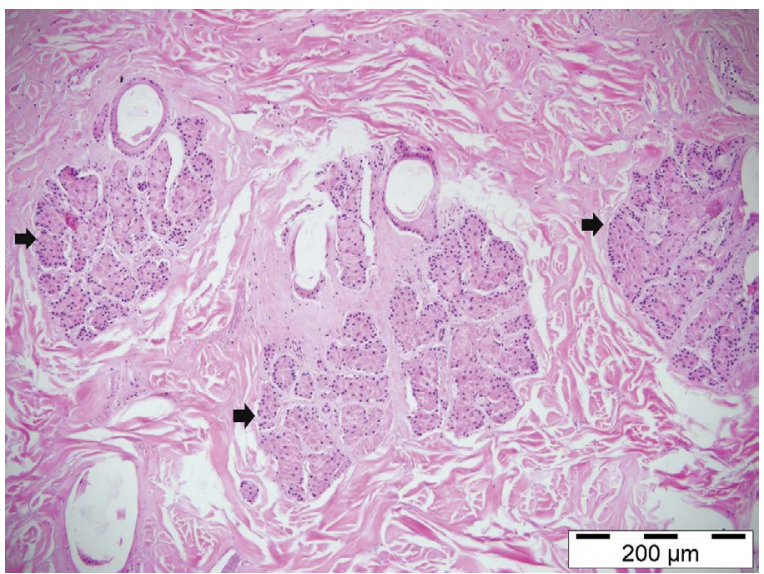

Figure 10. Lobe (alveolar) structure of the glands of the Abaza goats. Thick arrow: oil cloth-like structures, haematoxylin and eosin.

study, it was observed that these gland structures were in the back part of the middle part of the horn as we thought that there might be horn glands. It was determined that these gland structures were located parallel to the epidermis in the stratum superficiale layer of the dermis in both goat breeds (Figs. 8, 9). In the Abaza goats, these gland structures were found in the middle part of the superficial region of the dermis layer, in a more regular and broadly located lobed form (Fig. 10). In the Gurcu goats, the localisation of these glands was more superficial, in other words, close to the epidermis and had a narrower structure with more lobes (Fig. 11). In both breeds, it was observed that the normal sebaceous glands were negligible in the regions containing this gland 


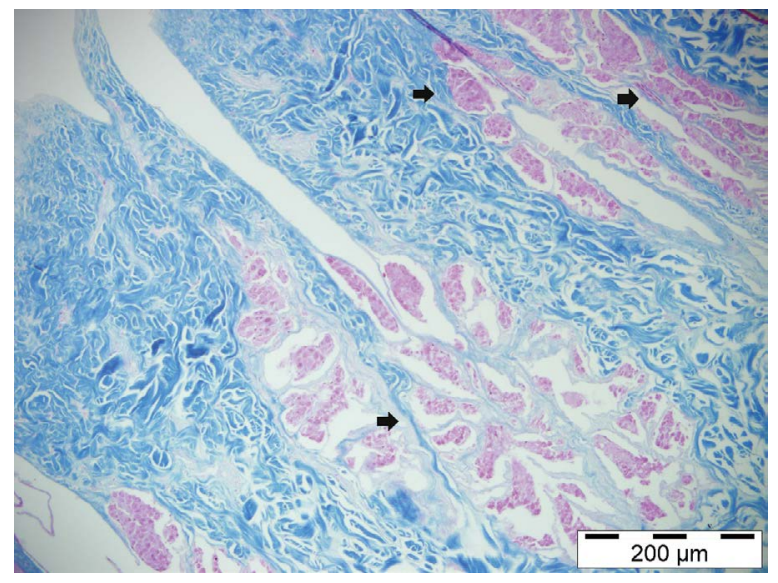

Figure 11. Multi-lobed structure of the glands of the Gurcu goats. Thick arrow: triple, similar to the sebaceous gland structures, $\times 10$.

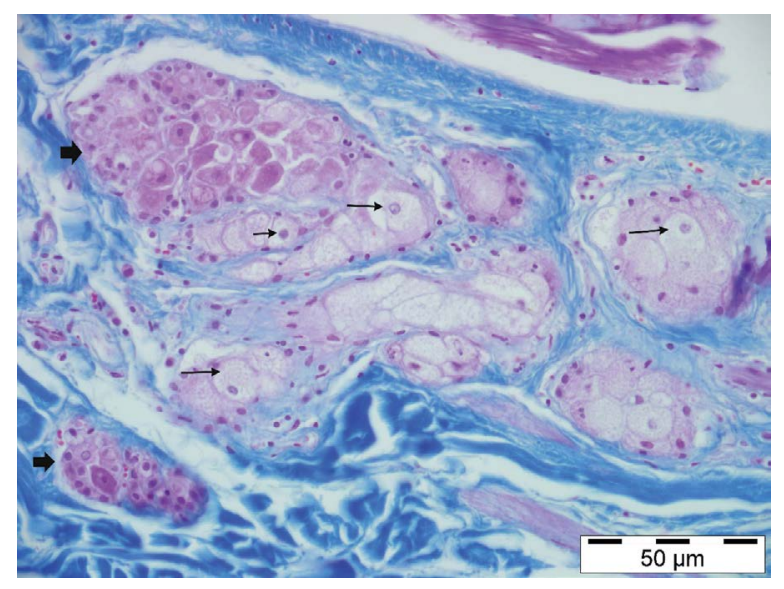

Figure 12. Different cell groups located between the fat cells in the dermis. Thick arrow: oil gland-like structures; triple $\times 40$.

structure. It was thought that these glands, which had more lobes and branched alveolar structures, may be the horn glands as they were different from the typical sebaceous glands found around the hair root. In some cases, these glands which were thought to be the horn glands and the sebaceous glands were found together; however, they contained cells with different structures and staining properties (Fig. 12). In addition, when the sebaceous gland structures of the two breeds were examined, it was observed that the fat cells in the Gurcu goats were structurally smaller than those of the Abaza goats.

\section{DISCUSSION}

In the present study, the front, back and side of the horn glands were determined by cross-section in two different, but morphologically similar, breeds of the Abaza goat and Gurcu goat.
Lancker et al. [12] reported that the horned glands of the polled goat breeds were located on the caudal surface of the head under the skin folds [12]. This, however, was not observed in the present study for the Abaza goats or the Gurcu goats.

In a study on the horn glands of West African dwarf goats and red Sokoto goats conducted in Nigeria, the horn glands were reported to be simple or branched alveolar sebaceous glands. It was stated that the horn glands were structurally similar to the sebaceous glands located in other parts of the body in both the males and the females. As with other sebaceous glands, the horn glands are often said to be associated with hair follicles. However, in a few cases, it has been reported that one or more sebaceous glands are associated with a hair follicle, and each of these glands has a separate secretion portion, as well as a separate secretory channel opening to the hair follicle. In the Abaza and Gurcu goats, it was observed that the glands were simply branched and alveolar, and their secretions were drained through the hair follicles [5]. The structures specified as horn glands in the present study were found to be similar to the glands of the Nigerian goat breeds. However, unlike the breeds in Nigeria, a secretion channel was not found in the Abaza and Gurcu goats.

Some authors reported that two sebaceous glands associated with a single hair follicle had two lobes $[2,10]$. This was found to be similar for the Abaza goats examined in the present study; however, more lobed glands were found around a hair follicle in the Gurcu goats.

In a study conducted on American goats, horn glands and other sebaceous glands were compared and it was reported that the sebaceous glands had larger alveoli [13]. In the present study, it was seen that the sebaceous glands had more alveoli than the horn glands in the goat breeds, and that the structures that were thought to be horn glands in both of the goat breeds were more than the sebaceous glands.

West African dwarf goats are found in the tropical forest areas of Southern Nigeria, while red Sokoto goats are found in the savannah regions of Northern Nigeria. It was reported that climate can have an impact on the glands of these goats, and that seasonal changes alter the size of the British and American goat horn glands $[2,10]$.

It has been reported that the differences in the cross-sectional area of the horn glands and other sebaceous glands were more prominent in male Nigerian 
goats than the female ones and that these glands were involved in odour production [5]. In the present study, the reason for the glands being larger and more active was thought to be because the samples used were collected during the breeding season of the goats.

\section{CONCLUSIONS}

In the present study, horn glands could not be detected macroanatomically in the Abaza and Gurcu goat breeds; however, they were found histologically and their structure were seen to be similar to those mentioned in the literature. This study can help guide future studies.

\section{REFERENCES}

1. Anonim. Abaza keçisi koruma altında, Artvin il Gıda Tarım ve Hayvancılık Müdürlüğü (28.11.2016).

2. Bal HS, Ghoshal NG. The scent glands of the goat (Capra hircus). Zentralbl. Veter-inirmed C. 1976; 5(104).

3. Batu S. Türkiye Keçi Irkları. Ankara Üniversitesi Veteriner Fakültesi Yayınları, Ankara. 1951.

4. Brouwer E, Nijkamp HJ. Volatile acids in the secretion products, hair grease, of the skin. Biochem J. 1952; 52(1): 54-58, doi: 10.1042/bj0520054, indexed in Pubmed: 13018162.

5. Chukwu DO, Ihemelandu EC. Morphometric studies on horn glands of Nigerian breeds of goat. Small Ruminant Res. 1989; 2(4): 367-374, doi: 10.1016/09214488(89)90031-x.

6. Dalga S. Topographic and morphometric study of the mental foramina of Abaza goats with its clinical implica- tion for regional anesthesia. Folia Morphol. 2019 [Epub ahead of print], doi: 10.5603/FM.a2019.0122, indexed in Pubmed: 31750539.

7. Ebling F. The effects of testosterone and oestradiol on the sebaceous glands and epidermis of therat. J Embryol Exp Morphol. 1957; 5: 74-82.

8. Erençin Z. Genel Histoloji, Ankara Üniversitesi Veteriner Fakültesi Yayınlar. 1958; 98.

9. French MH. Observations on the goat. FAO, Rome. 1970; 2.

10. Jenkinson DM, Blackburn PS, Proudfoot R. Seasonal changes in the skin glands of the goat. Br Vet J. 1967; 123(12): 541-549, doi: 10.1016/s0007-1935(17)39654-9.

11. Kuru M, Kuru B, Kulaksız R, et al. Abaza Keçilerinde Progesteron Destekli Östrus Senkronizasyonunun Bazı Reprodüktif Parametrelere Etkileri. Kocatepe Vet J. 2017; 10(3): 164-171.

12. Lancker S, Van den Broeck W, Simoens P. Morphology of caprine skin glands involved in buck odour production. Vet J. 2005; 170: 351-358, doi: 10.1016/j.tvjl.2004.08.017.

13. Sar M, Calhoun ML. Microscopic anatomy of the integument of the common erican goat. Am J Vet Res. 1966; 27: 444-456.

14. Sezgin E, Kopuzlu S, Yüksel S. Abaza keçisi. Ulusal Keçicilik Kongresi, Çanakkale. 2010: 241-244.

15. Strauss JS, Kligman AM, Pochi PE. The effect of androgens and estrogens on human sebaceous glands. J Invest Dermatol. 1962; 39: 139-155, doi: 10.1038/jid.1962.94, indexed in Pubmed: 13917704.

16. Yalçın BC, Türkiye'de yetiştirilen keçi ırkları. "Koyun-Keçi Hastalıkları ve Yetiştiriciliği", Ed; Aytuğ CN, Alaçam E, Özkoç Ü, Yalçın BC, Gökçen H, Türker H, Tüm Vet. Hayvancılık Hizmetleri Yayını, Teknografik Matbaası, İstanbul, Türkiye, 1990. 